ORIGINAL ARTICLE

\title{
Hyperinsulinaemic hypoglycaemia in preterm neonates
}

\author{
K Hussain, A Aynsley-Green
}

See end of article for

authors' affiliations

Arch Dis Child Fetal Neonatal Ed 2004;89:F65-F67

.....................

Correspondence to:

Dr Hussain, Institute of

Child Health, University

College London, 30

Guilford Street, London

WCIN IEH, ÚK;

K.Hussain@ich.ucl.ac.uk

\begin{abstract}
Hyperinsulinism in infancy (HI) is an important cause of severe and recurrent hypoglycaemia in newborn infants. It usually appears in infants born at term, and only one case of its occurrence in a prematurely born infant has been reported as an incidental finding. This is a report of seven infants born at 3136 weeks gestation who experienced severe persistent hyperinsulinism. Two infants were large for dates. All infants were difficult to manage, suggesting that the occurrence of $\mathrm{HI}$ with prematurity may be associated with a particularly aggressive illness. HI should be considered in the differential diagnosis of severe hypoglycaemia in preterm infants.
\end{abstract} Accepted

17 February 2003

$\mathrm{H}$ yperinsulinism in infancy $(\mathrm{HI})$ is a rare cause of recurrent and severe hypoglycaemia in the newborn infant and during the first postnatal weeks. ${ }^{1}$ Neonates with persistent HI are usually born at term and may have a birth weight that is either appropriate for gestational age or large for dates. Some of the latter neonates with HI have a characteristic appearance, being macrosomic and plethoric, resembling strikingly the appearance of an infant of a diabetic mother. This appearance suggests that the HI in these infants had been present for some time before birth.

$\mathrm{HI}$ has also been reported previously in intrauterine growth retarded infants ${ }^{2}$ and in those suffering from perinatal asphyxia. ${ }^{3}$ In these conditions, the HI is usually a transient phenomenon and usually settles within a few days of delivery. The mechanisms responsible for the HI seen in these conditions are not clear. Transient HI may also occur in infants born to mothers with diabetes mellitus, ${ }^{4}$ in infants with Rhesus isoimmunisation, ${ }^{5}$ and in infants with the Beckwith-Weidemann syndrome. ${ }^{6}$

Although we have reported incidentally the occurrence of persistent $\mathrm{HI}$ in one preterm infant, ${ }^{7}$ its presentation before term has been considered to be a rare event.

We now report our experience of persistent HI occurring in a series of preterm babies. Our cases illustrate not only the occurrence of $\mathrm{HI}$ in preterm babies but also the variability of their response to medical treatment. The combination of HI with prematurity may also be associated with a more aggressive and severe form of hyperinsulinism.

PATIENTS, INVESTIGATIONS, AND CLINICAL DATA The London Centre for Paediatric Endocrinology and Metabolism is a national and international referral centre for HI. We present the clinical and diagnostic features of seven babies who presented with HI in the neonatal period. This group consisted of preterm babies with gestational ages of 31-36 weeks (table 1), all of whom developed hypoglycaemia at times after birth ranging from less than 1 hour to 72 hours of age. The birth weights of these babies were 1740$4040 \mathrm{~g}$. Two were macrosomic, and five were appropriate size for gestational age. All of the babies were referred over a three year period. Two were referred from abroad, three were local referrals, and two were referred from outside the local region.

All were subjected to the investigation protocol detailed previously $^{8}$ focusing on defining the infusion rate of glucose needed to maintain normoglycaemia, and the metabolic and

endocrine milieu documented during fast induced hypoglycaemia. All infants showed a considerably increased glucose infusion requirement, ranging from 14 to $22 \mathrm{mg} / \mathrm{kg} / \mathrm{min}$. The highest glucose requirement was in one of the preterm babies that had a weight that was appropriate for gestational age. All infants showed exquisite sensitivity to being deprived of energy in the form of intravenous glucose administration. In all infants the laboratory blood glucose concentration fell to $<2.6 \mathrm{mmol} / \mathrm{l}$ within 30 minutes of the decrease in glucose infusion rate.

Table 2 shows the metabolic and endocrine profiles documented at that time. All babies had biochemical profiles reflecting hyperinsulinaemic, hypoketotic, hypofattyacidaemic hypoglycaemia with increased glucose requirements. The plasma ammonia concentration was normal in all of the babies. Plasma cortisol levels were measured in five of the babies and were found to be inappropriately low at the time of hypoglycaemia.

All infants were treated with diazoxide $(5-20 \mathrm{mg} / \mathrm{kg} /$ day $)$ and chlorothiazide $(7-10 \mathrm{mg} / \mathrm{kg} /$ day $)$. Only three infants responded sufficiently well to a starting dose of diazoxide of $10 \mathrm{mg} / \mathrm{kg} /$ day with chlorothiazide $7 \mathrm{mg} / \mathrm{kg} /$ day to allow the intravenous glucose support to be discontinued. In these infants, the effect of treatment was evident within 48 hours. It was possible to discontinue medical treatment in each of these infants after three to six months.

The remaining four infants failed to become glucose drip independent despite the dose of diazoxide being increased to $20 \mathrm{mg} / \mathrm{kg} /$ day and the introduction of continuous intravenous or subcutaneous infusions of glucagon $(1.0 \mu \mathrm{g} / \mathrm{kg} / \mathrm{h})$ and octreotide $(10 \mu \mathrm{g} / \mathrm{kg} /$ day $)$. All four infants were subjected to a $95 \%$ pancreatectomy to control the hypoglycaemia. One of these infants required the use of nifedipine $(0.75 \mathrm{mg} / \mathrm{kg} /$ day) to prevent the recurrence of hypoglycaemia. ${ }^{7}$ Histological examination of the pancreas showed changes consistent with the diffuse form of HI. ${ }^{9}$ Electrophysiology studies using patch clamp techniques on the resected pancreas showed complete loss of function of the $\mathrm{K}_{\mathrm{ATP}}$ channel in the $\beta$ cell membrane, which is now known to be the most common cause of HI. ${ }^{10}$

\section{DISCUSSION}

Congenital HI is a heterogeneous disease with several different underlying pathophysiologies. ${ }^{11}$ In about $40 \%$ of cases, it is due to an abnormality of the $\mathrm{K}_{\mathrm{ATP}}$ channel in the $\beta$ cell membrane. This channel is composed of two subunits, 
Table 1 Clinical details of the seven preterm babies with hyperinsulinism

\begin{tabular}{llllllll}
\hline & $\mathbf{1}$ & $\mathbf{2}$ & $\mathbf{3}$ & $\mathbf{4}$ & $\mathbf{5}$ & $\mathbf{6}$ & $\mathbf{7}$ \\
\hline Sex & $\mathrm{M}$ & $\mathrm{F}$ & $\mathrm{F}$ & $\mathrm{M}$ & $\mathrm{M}$ & $\mathrm{M}$ & $\mathrm{F}$ \\
Gestational age (weeks) & 31 & 34 & 36 & 33 & 36 & 36 & 36 \\
Birth weight (g) & 1740 & 1800 & 2150 & 3300 & 3780 & 4250 & 4040 \\
Apgar scores (1 and 5 min) & 8,9 & 7,9 & 7,9 & 7,9 & 8,9 & 9,9 & 8,9 \\
Age at presentation (h) & 3 & 1 & 2 & 72 & 1 & $<1$ & 1 \\
Mode of delivery & $\mathrm{CS}$ & $\mathrm{CS}$ & $\mathrm{CS}$ & $\mathrm{CS}$ & $\mathrm{NVD}$ & $\mathrm{NVD}$ & $\mathrm{NVD}$ \\
Maximum glucose required & 22 & 19 & 19 & 14 & 21 & 19 & 21 \\
(mg/kg/min) & $\mathrm{SP}$ & $\mathrm{D} / \mathrm{C}$ & $\mathrm{D} / \mathrm{C}$ & $\mathrm{SP}$ & $\mathrm{SP}$ & $\mathrm{SP}$ & $\mathrm{D} / \mathrm{C}$ \\
Treatment & $\mathrm{SP}$ & &
\end{tabular}

CS, Caesearean section; NVD, normal vaginal delivery; SP, subtotal pancreatectomy; D, diazoxide; C, chlorothiazide.

SURl and KIR6.2, which are encoded by genes located on chromosome $11 \mathrm{p} 15.1$. This channel plays a fundamental role in stimulus secretion coupling, which links the metabolism of glucose to the secretion of insulin. Mutations in the genes encoding these two proteins perturb the function of the $\mathrm{K}_{\mathrm{ATP}}$ causing unregulated insulin release.

$\mathrm{HI}$ is the most common cause of severe and persistent hypoglycaemia in neonates and infants. ${ }^{12}$ Neonates with HI are especially prone to the adverse complications of hypoglycaemia because of their inability to generate alternative fuels, such as ketone bodies, because of the dominant effects of insulin. $\mathrm{HI}$ is associated with a very high incidence of neurological handicap; up to $20 \%$ of infants with this condition may have persistent neurological handicaps. ${ }^{13}$ Therefore this disease is a devastating disorder with profound implications for the child and its family.

The occurrence of HI in preterm infants has been thought to be a rare association, with only one patient (our case 1) having been reported previously. ${ }^{7}$ Our series of seven infants suggests that the diagnosis of HI should be considered in any preterm infant with recurrent and persistent hypoglycaemia, whether appropriate size or large for dates. It is interesting that macrosomia was noted in only the two infants with the longest periods of gestation-36 weeks. The appropriateness of dates in the other five infants could imply either that they had not experienced intrauterine hyperinsulinism or that its occurrence does not lead to macrosomia until the last weeks of pregnancy.

All the babies had a normal plasma ammonia concentration, excluding the recently described syndrome of hyperinsulinaemic hyperammonaemic hypoglycaemia. ${ }^{14}$

The patients all showed the typical biochemical profile of hyperinsulinaemic, hypoketotic, hypofattyacidaemic hypoglycaemia with increased glucose requirements that is seen in infants born at term and in older infants. ${ }^{8}$ However, there are some potential difficulties in interpreting such data in preterm infants. Thus, Hawdon et al ${ }^{15}$ have emphasised that the normal tight relation between blood glucose and plasma insulin concentrations seen in older children and adults may not be so evident during the neonatal period, and this is particularly so in preterm infants. This point is of fundamental importance in considering the diagnosis of $\mathrm{HI}$ in the neonatal period, when data from age matched control subjects needs to be considered. ${ }^{16}$ Although all of our babies had raised insulin concentrations, it is important to emphasise that an appropriate insulin concentration for normoglycaemia becomes inappropriate in the presence of hypoglycaemia. ${ }^{17}$ Plasma insulin levels do not need to be very high for the diagnosis of HI. The demonstration of any measurable insulin in a hypoglycaemic sample is strong evidence for a failure of basal insulin control. ${ }^{17}$ Of particular significance in confirming the diagnosis is the increased glucose requirement. All of these babies had greatly increased needs, and we would suggest that this is a particularly important pointer to the diagnosis.

Our cases illustrate another key point, namely that preterm babies born with HI can have birth weights that are either appropriate for gestational age or increased. The absence of macrosomia is not an argument against the diagnosis.

Of the babies that were macrosomic, three required a $95 \%$ pancreatectomy to control the hypoglycaemia. The pancreases from these babies showed no responsiveness to diazoxide in vitro. These findings imply that the underlying cause of $\mathrm{HI}$ is the same in babies whether they are appropriate size for gestational age or macrosomic.

The mechanism of insulin dysregulation in those babies who responded to diazoxide is not clear. The fact that they responded to diazoxide implies that the $\mathrm{K}_{\mathrm{ATP}}$ must be intact and the excessive insulin secretion must originate through another mechanism. These mechanisms may well involve $\mathrm{K}_{\text {ATP }}$ channel independent pathways of insulin secretion. ${ }^{18}$

It is interesting to note that all of these babies in whom the plasma cortisol concentration was measured showed low cortisol levels at the time of hypoglycaemia. This may be

Table 2 Results of the diagnostic fast and intermediary metabolites in seven preterm babies with hyperinsulinism

\begin{tabular}{|c|c|c|c|c|c|c|c|}
\hline & 1 & 2 & 3 & 4 & 5 & 6 & 7 \\
\hline Glucose (mmol/l) & 1.1 & 2.5 & 2.2 & 1.8 & 1.7 & 1.8 & 1.7 \\
\hline Insulin (mU/I) & 15 & 16.4 & 13.1 & 12.6 & 8.0 & 13.8 & 28.5 \\
\hline NEFA (mmol/l) & 0.13 & 0.16 & 0.14 & 0.05 & 0.12 & 0.17 & 0.05 \\
\hline $3 \beta$-Hydroxybutyrate $(\mathrm{mmol} / \mathrm{l})$ & $<0.05$ & $<0.05$ & $<0.05$ & $<0.05$ & $<0.05$ & $<0.05$ & $<0.05$ \\
\hline Cortisol (nmol/l) & 75 & 155 & 67 & NM & 111 & NM & 350 \\
\hline Growth hormone (mU/I) & 60 & 23.6 & 36.6 & NM & 11.1 & 12.4 & 68.8 \\
\hline Ammonia ( $\mu \mathrm{mol} / \mathrm{l}$ ) (normal 50) & 45 & 45 & 40 & 50 & 48 & 42 & 50 \\
\hline Lactate $(\mathrm{mmol} / \mathrm{l})$ & 1.3 & 1.2 & 1.5 & 1.9 & 2.0 & 1.5 & 1.9 \\
\hline $\begin{array}{l}\text { Branched chain amino acids } \\
\text { Urine organic acids } \\
\text { Acylcarnitines }\end{array}$ & \multicolumn{7}{|c|}{$\begin{array}{l}\text { Suppressed branch chain amino acids in all cases } \\
\text { Normal for all } \\
\text { Normal for all }\end{array}$} \\
\hline
\end{tabular}

NM, Not measured; NEFA, non-esterified fatty acids. 
related to the fact that they were preterm, with resulting immaturity in the cortisol secretory pathways in the adrenal gland. Preterm neonates are able to generate significant cortisol counterregulatory hormonal responses to stress, ${ }^{19}$ but a proportion of preterm infants may have inadequate adrenal response to stress in early postnatal life..$^{20}$ The plasma cortisol concentrations maybe inappropriately low in some ill preterm infants because of the inability of the extremely premature brain to recognise the stress of the illness or because of inadequate hypothalamic secretion of corticotrophin releasing hormone. However, it is also possible that they may show the abnormal cortisol counterregulatory hormonal response to hypoglycaemia that we have shown in term neonates with $\mathrm{HI}^{21}$ Further work is needed to define whether the hypocortisolaemia requires treatment, although there is no evidence that cortisol treatment improves blood glucose homoeostasis in full term or older infants (K Hussain, unpublished).

It is noteworthy that the management problems of HI seen in full term infants were substantially more difficult in these small infants in whom the need for very high glucose infusion rates was compounded by poor venous access and recurrent infections in central venous catheters. Additional problems were limited blood volume and the practical problems of multiple heel pricks. The transition to enteral feeding was particularly problematic because of concurrent intestinal dysmotility. There were additional difficulties in teaching the infants to suck from a teat. All of these difficulties led to prolonged hospital stay in the nondiazoxide responsive infants (more than three months). It is too soon to be confident of the long term neurological prognosis, but at least two of the infants are severely handicapped.

We conclude that HI should be considered in the diagnosis of any preterm infant presenting with severe hypoglycaemia. Of especial note is the importance of the glucose infusion requirement as a pointer to the diagnosis. Infants may need near total pancreatectomy to control the hypoglycaemia, and the formidable management difficulties of the disease that are well recognised in full term or older infants ${ }^{8}$ are accentuated in these preterm babies. Neonatologists should not underestimate the practical difficulties of the diagnosis in such babies, and we recommend that they should be transferred to a centre that has the full panoply of expertise to support effective management.

\section{ACKNOWLEDGEMENTS}

Some of this work was undertaken by Great Ormond Street Hospital for Children NHS Trust who received a proportion of its funding from the NHS Executive; the views expressed in this publication are those of the authors and are not necessarily those of the NHS Executive.

\section{Authors' affiliations}

K Hussain, A Aynsley-Green, London Centre for Paediatric Endocrinology and Metabolism, Great Ormond Street Hospital for Children NHS Trust, London WCIN 3JH, UK and Institute of Child Health, University College London, London WCIN 1EH, UK

\section{REFERENCES}

1 Soltesz G, Aynsley-Green A. Hyperinsulinism in infancy and childhood. In: Advances in internal medicine and paediatrics. Berlin: Springer, 1984:51:115-202.

2 Collins JE, Leonard JV, Teale D, et al. Hyperinsulinaemic hypoglycaemia in small for dates babies. Arch Dis Child 1990;65:1118-20.

3 Collins JE, Leonard JV. Hyperinsulinism in asphyxiated and small for dates infants with hypoglycaemia. Lancet 1984;ii:311-13.

4 Sperling MA, Menon RK. Infant of the diabetic mother. Curr Ther Endocrinol Metab 1994;5:372-6.

5 Miller HC, Johnson RD, Durlacher SH. A comparison of newborn infants with erythroblastosis fetalis with those born to diabetic mothers. J Pediatr 1944;24:603-15.

6 Moncrieff MM, Lacey KA, Malleson PN. Management of prolonged hypoglycaemia in Beckwiths syndrome. Postgrad Med J 1977;53:159-61.

7 Lindley KJ, Dunne MJ, Kane C, et al. lonic control of the B-cell function in nesidioblastosis, a possible role for calcium channel blockade. Arch Dis Child 1996:74:373-8.

8 Aynsley-Green A, Hussain K, Hall J, et al. The practical management of hyperinsulinism in infancy. Arch Dis Child Fetal Neonatal Ed 2000;82:F98-107.

9 Rahier J, Guiot Y, Sempoux C. Persistent hyperinsulinaemic hypoglycaemia of infancy: a heterogeneous syndrome unrelated to nesidioblastosis. Arch Dis Child Fetal Neonatal Ed 2000;82:F108-12.

10 Kane C, Shepherd RM, Squires PE, et al. Loss of functional $K_{\text {ATP }}$ channels in $\beta$ cells causes persistent hyperinsulinaemic hypoglycaemia on infancy. Nat Med 1996:2:1344-7.

11 Glaser B, Thornton P, Otonkoski T, et al. Genetics of neonatal hyperinsulinism. Arch Dis Child Fetal Neonatal Ed 2000;82:F79-86.

12 Aynsley-Green A, Soltesz G. Hypoglycaemia in infancy and childhood. In: Chambers T, Aynsley-Green A, eds. Current reviews in paediatrics. Edingurgh: Churchhill-Livingstone, 1985.

13 Meissner T, Brune W, Mayatepak E. Persistent hyperinsulinaemic hypoglycaemic of infancy: therapy, clinical outcome and mutational analysis. Eur J Pediatr 1997:156:754-7.

14 Stanley CA, Lieu YK, Hsu BY, et al. Hyperinsulinism and hyperammonaemia in infants with regulatory mutations of the glutamate dehydrogenase gene. N Engl J Med 1998;338:1352-7.

15 Hawdon JM, Hubbard M, Hales CN, et al. Use of specific immunoradiometric assay to determine preterm neonatal insulin-glucose relations. Arch Dis Child Fetal Neonatal Ed 1995;73:F166-9.

16 Hawdon JM, Aynsley-Green A, Ward Platt MP. The role of pancreatic insulin secretion in neonatal glucoregulation. 2. Infants with disordered glucose homeostasis. Arch Dis Child 1993:68:280-5.

17 Aynsley-Green A, Polak JM, Bloom SR, et al. Nesidioblastosis of the pancreas: definition of the syndrome and the management of the severe neonatal hyperinsulinaemic hypoglycaemia. Arch Dis Child 1982;56:496-598.

18 Gembal M, Detimary P, Gilon P, et al. Mechanisms by which glucose can control insulin release independently from its action on adenosine triphosphate-sensitive K channels in mouse B-cells. J Clin Invest 1993;91:871-80.

19 Hughes D, Murphy JF, Dyas J, et al. Blood spot glucocorticoid concentrations in ill preterm infants. Arch Dis Child 1987:62:1014-18.

$20 \mathrm{Ng} \mathrm{PC}$, Lam CW, Lee $\mathrm{CH}$, et al. Reference ranges and factors affecting the human corticotropin-releasing hormone test in preterm, very low birth weight infants. J Clin Endocrinol Metab 2002 Oct;87:4621-8.

21 Hussain K, Hindmarsh P, Aynsley-Green A. Neonatal hyperinsulinism is associated with abnormal cortisol responses to hypoglycaemia. Horm Res 2000;53(suppl 2):26. 